\title{
Evidence of a dominant role for low osmolality in the efficacy of cereal based oral rehydration solutions: studies in a model of secretory diarrhoea
}

\author{
A V. Thillainayagam, S Carnaby, J A Dias, M L Clark, M J G Farthing
}

\begin{abstract}
Clinical trials suggest that including naturally occurring complex carbohydrate in oral rehydration solutions (ORS) in place of glucose increases water absorption and reduces stool volume during acute diarrhoea. The mechanisms for this greater clinical efficacy has not been established. This study examined the ability of two hypotonic rice based ORS, RS-ORS (137 mOsm/kg) and RPORS (143 mOsm/kg), and HYPO-ORS (240 $\mathrm{mOsm} / \mathrm{kg}$ ) a glucose equivalent ORS, to effect water absorption by in vivo perfusion of normal and secreting rat small intestine. The results were compared with those for two widely used conventional hypertonic ORS, WHO-ORS (331 mOsm/kg) and UK-ORS (310 $\mathrm{mOsm} / \mathrm{kg}$ ). In the normal intestine, water absorption was similar from WHO-ORS (87.4 (45.1-124.6) $\mu \mathrm{l} / \mathrm{min} / \mathrm{g}$; median and interquartile range) and UK-ORS (57.6 (41.5-87)) but less than from the hypotonic solutions (p<0.02); water absorption from RS-ORS (181.8 (168.5-193.8)) and RP-ORS (195.7 (179.3-207.9)) was similar but less than from HYPO-ORS (241.3 (230.6-279.7); p<0.005). In the secreting intestine, all ORS reversed net secretion of fluid to net absorption; the hypotonic solutions, HYPO-ORS (105.2 (95.2111)), RS-ORS (127.7 (118.3-169.4)) and RPORS (133.7 (122.1-174.5)), produced more water absorption $(p<0.005)$ than the hypertonic solutions WHO-ORS (47.1 (29-75.9)) and UK-ORS (24.9 (18.4-29.4)). The rice based solutions promoted most water absorption in secreting intestine $(p<0.007)$. These data indicate that low osmolality is of primary importance in mediating the increased water absorption from cereal based ORS.

(Gut 1993; 34: 920-925)
\end{abstract}

Acute infectious diarrhoea continues to be a major cause of morbidity throughout the world,

TABLE I Composition of oral rehydration solutions perfused

\begin{tabular}{lcccccr}
\hline Solute (mmolll) & $\begin{array}{l}\text { WHO- } \\
\text { ORS }\end{array}$ & $\begin{array}{l}\text { UK- } \\
\text { ORS }\end{array}$ & $\begin{array}{l}\text { HYPO- } \\
\text { ORS }\end{array}$ & $\begin{array}{l}\text { RS- } \\
\text { ORS }\end{array}$ & $\begin{array}{l}\text { RP- } \\
\text { ORS }\end{array}$ & PES \\
\hline Sodium & 90 & 35 & 60 & 60 & 60 & 140 \\
Potassium & 20 & 20 & 20 & 20 & 20 & 4 \\
Chloride & 80 & 35 & -60 & 60 & 60 & 104 \\
Bicarbonate & 30 & 20 & - & - & - & 40 \\
Citrate & $-\overline{1}$ & 200 & 90 & 10 & 10 & - \\
Glucose & 11 & - & - & $16 \cdot 3 \star$ & $17 \cdot 4 \star$ & - \\
Rice starch/powder (g) & 331 & 310 & 240 & 137 & 143 & 288 \\
Osmolality (mOsm/kg) & & & &
\end{tabular}

^Yield $90 \mathrm{mmol} / \mathrm{l}$ glucose after complete hydrolysis.

WHO=World Health Organisation; UK=United Kingdon; $\mathrm{HYPO}=$ hypotonic; $\mathrm{RS}=$ rice starch $\mathrm{RP}=$ ground rice powder; $\mathrm{PES}=$ plasma electrolyte solution; $\mathrm{ORS}=$ oral rehydration solutions. particularly in preschool children, with an unacceptable mortality in this age group approaching 4 million each year. ${ }^{1}$ Rehydration with oral rehydration solutions (ORS) containing monomeric glucose as substrate has been considered the most important therapeutic breakthrough of this century. ${ }^{2}$ Although highly effective for rapid rehydration when given by mouth, standard glucose electrolyte ORS do not reduce the volume or duration of the diarrhoea ${ }^{3}$ and may actually increase stool volumes. This can discourage the mother or other attendant who administers $\mathrm{ORS}^{4}$ and compromise the rehydration process. Several clinical trials with cereal based $\mathrm{ORS}^{5-14}$ have shown dramatic improvements over conventional glucose electrolyte oral rehydration treatment with reduced duration and severity of diarrhoea and an associated reduction in the volume of ORS required for rehydration. The reasons why cereal based ORS have been so successful has not been examined but a number of possible mechanisms have been proposed including increased substrate availability without increased osmolality, ${ }^{4}$ kinetic advantage of oligosaccharides over glucose monomers, ${ }^{15} 16$ and low osmolality. ${ }^{17-20}$

To explore these possible mechanisms further we studied the ability of hypotonic cereal based ORS and a glucose equivalent monomeric ORS to effect water and electroyte absorption in an animal model and compared these findings with two widely used conventional glucose-electrolyte ORS.

\section{Materials and methods}

ORAL REHYDRATION SOLUTIONS STUDIED

Table I shows the composition of the ORS perfused. We used two conventional standard ORS - namely, the World Health Organisation ORS (WHO-ORS) and the ORS formulation recommended in the British Pharmacopoeia (UK-ORS), which until recently was the most widely used ORS in the United Kingdom. A hypotonic ORS (HYPO-ORS) has been previously studied by our group ${ }^{19}$ and is now recommended by the European Society for Paediatric Gastroenterology and Nutrition ${ }^{21}$ as being the optimal formulation for European children. Rice starch (Sigma Chemical Co) and rice powder (local supermarket) ORS were prepared with an identical electrolyte composition and glucose content (after complete hydrolysis) to HYPO-ORS. Thus we were able to examine the effects of presenting the intestine with a similar glucose load but in monomeric or polymeric form with an obligatory reduction in 


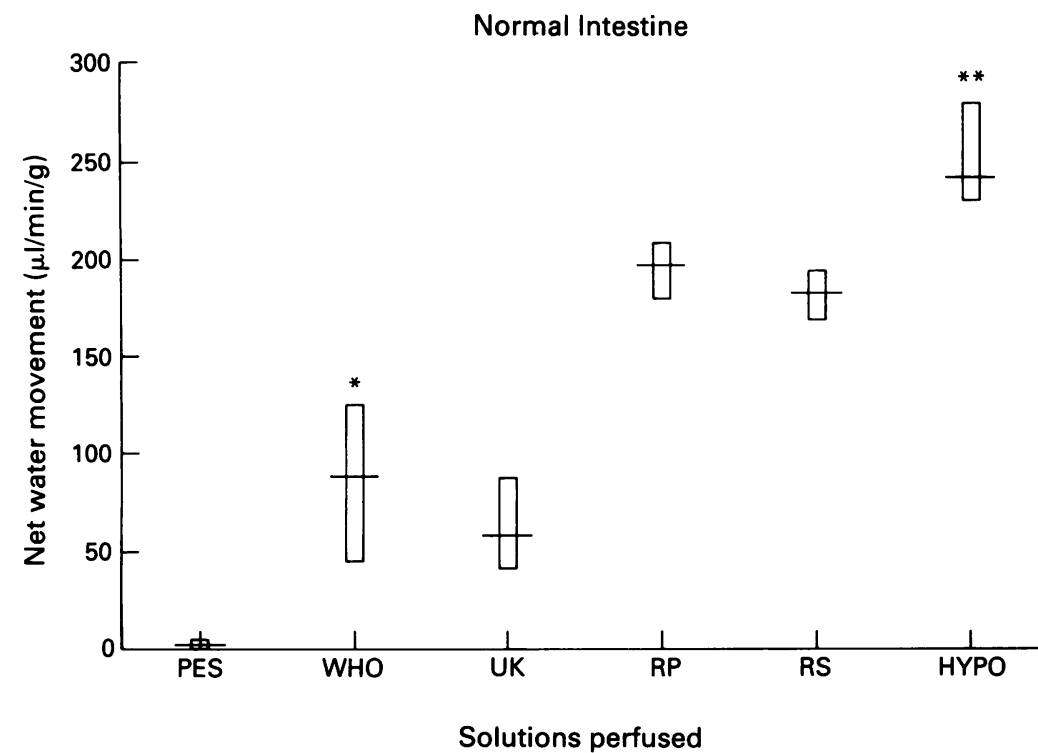

Figure 1: Net water movement in normal rat small intestine. Data are presented as median and interquartile range. ${ }^{\star} W H O-O R S$ similar to UK-ORS but less than $H Y P O-O R S, R P-O R S$ and $R S$-ORS; $p<0.02 ;{ }^{\star} H Y P O-O R S$ greater than RP-ORS and RS-ORS; $p<0.005$

osmolality accompanying the last. Comparison was also possible with the standard United Kingdom and developing world ORS.

\section{INTESTINAL PERFUSION OF NORMAL AND} SECRETING RAT SMALL INTESTINE Adult male Wistar rats (180-240 g) were fasted for 18 hours with free access to water. Anaesthesia was induced by intraperitoneal injection of sodium pentobarbitone $(60 \mathrm{mg} / \mathrm{kg})$ and maintained as necessary by interval intramuscular injection $(30 \mathrm{mg} / \mathrm{kg}$ ). Body temperature was measured with rectal thermometer and maintained with an underlying heat pad. After laparotomy cannulae were inserted proximally by duodenotomy and distally by terminal ileotomy as described previously. ${ }^{22}{ }^{23}$ Gentle lavage with warm isotonic saline $\left(37^{\circ} \mathrm{C}\right)$ and air was used to clear the entire small intestine of residual contents before instilling $75 \mu \mathrm{g}$ of cholera toxin ${ }^{22}$ in

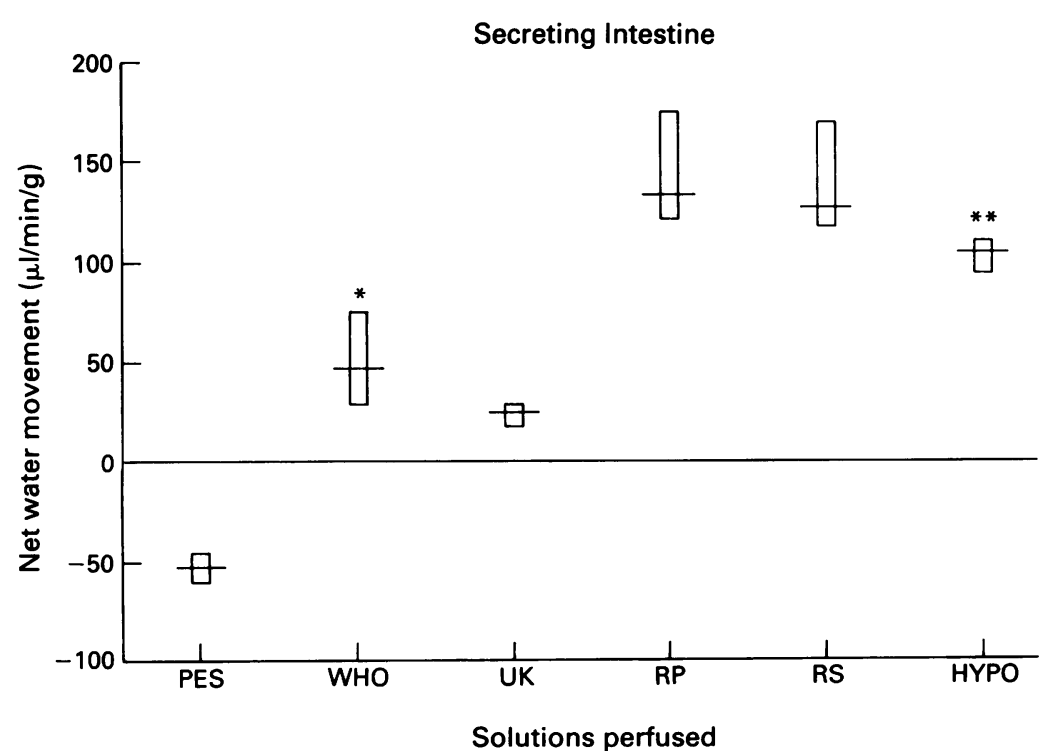

Figure 2: Net water movement in secreting rat small intestine. Data are presented as median and interquartile range ${ }^{\star} R P-O R S, R S-O R S$, and $H Y P O-O R S$ all greater than $W H O-O R S$ $p<0.005 ; \star \star H Y P O-O R S$ les than RP-ORS and RS-ORS; $p<0.007$.
$5 \mathrm{ml}$ of isotonic saline for two hours to induce a stable secretory state. ${ }^{24}$ For experiments with normal intestine, $5 \mathrm{ml}$ of plasma electrolyte solution (PES) were instilled in place of cholera toxin. The small intestine was then perfused with either PES or an ORS at $0.5 \mathrm{ml} / \mathrm{min}$ for one hour to ensure steady state conditions, after which three successive 10 minute collections of effluent were made from the distal cannula. At the end of the experiment the rats were killed by intracardiac injection of sodium pentobarbitone and exsanguination. The perfused segment of entire small intestine was removed, rinsed, blotted, and dessicated at $100^{\circ} \mathrm{C}$ to obtain the dry weight.

Mean marker recovery for 66 perfusions, comprising three consecutive 10 minute collections each, was $102 \cdot 1$ (SEM 1.48)\%. The percentage variation around the mean for $\left[{ }^{14} \mathrm{C}\right]-\mathrm{PEG}$ concentrations was $2.6(0.2) \%$ confirming that steady state conditions were indeed obtained. Each solution was perfused in eight to 10 rats with normal and with secreting intestine.

HYDROLYSIS OF RICE POWDER AND RICE STARCH Acid hydrolysis ${ }^{25}$ was performed wherein samples of effluent were incubated with hydrochloric acid $(1.0 \mathrm{~mol} / \mathrm{l})$ for two hours at $100^{\circ} \mathrm{C}$. At the end of the reaction sodium hydroxide $(1 \cdot 0$ $\mathrm{mol} / \mathrm{l}$ ) was added to neutralise the sample before glucose analysis. This method was effective at producing complete carbohydrate hydrolysis within two hours and was validated in preliminary experiments against an enzymatic method. ${ }^{16}$

\section{PERFUSATE ANALYSIS}

Sodium and potassium concentrations were analysed with flame photometry (Instrument Laboratories 943), chloride concentration by Chemlab CCMI chloride meter, bicarbonate concentration by Corning $\mathrm{CO}_{2}$ and glucose concentration by Beckman Glucose Analyser 2 . Osmolality was analysed with the vapour pressure technique with a Wescor 5500 osmometer. $\left[{ }^{14} \mathrm{C}\right]-\mathrm{PEG}$ concentrations were measured in triplicate by liquid scintillation spectroscopy in an LKB Wallac ultra-beta 1219 scintillation counter.

\section{CALCULATIONS}

Net solute and water movements were calculated by standard formulae ${ }^{26}$ from the measured solute concentration and $\left[{ }^{14} \mathrm{C}\right]-P E G$ counts in perfusate and effluent. The differences in transport data were analysed with the Wilcoxon rank test. All results were expressed as median and interquartile range. Two tailed tests were used throughout.

\section{Results}

WATER ABSORPTION

In normal intestine (Fig 1) water absorption was similar from WHO-ORS and UK-ORS but less than from HYPO-ORS and the rice based solu- 


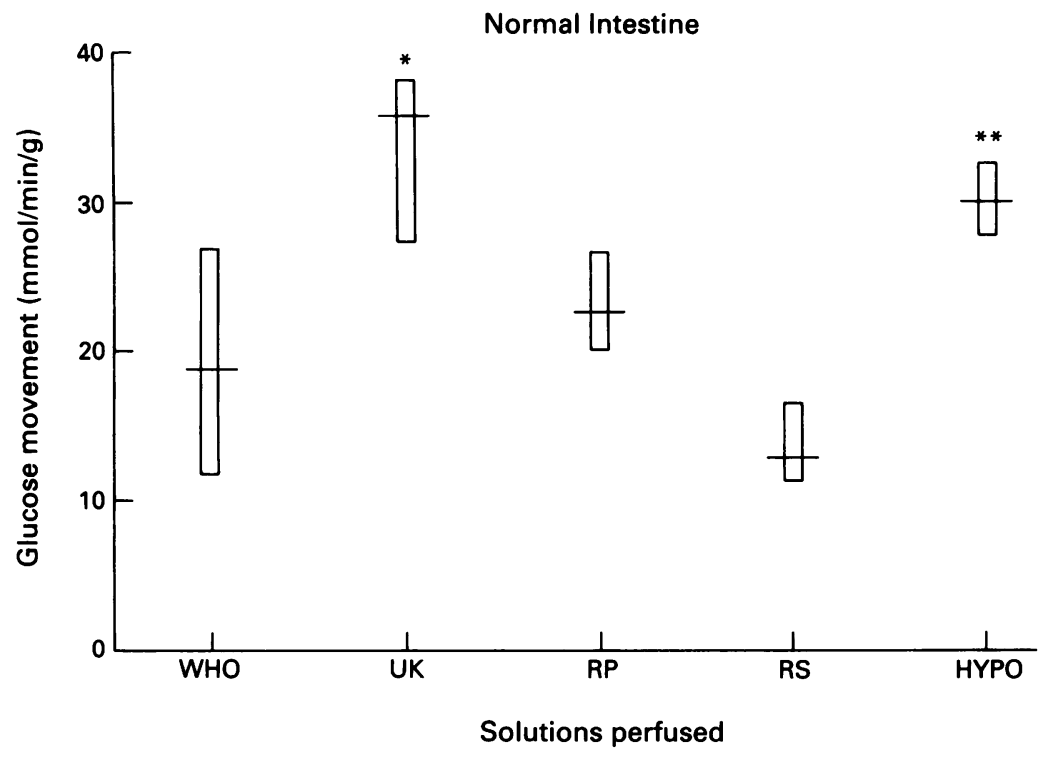

Figure 3: Net glucose movement in normal rat small intestine. Data are presented as median and interquartile range. ${ }^{\star} U K-O R S$ greater than $R P-O R S, R S-O R S$, and WHO-ORS; $p<0.002 ;{ }^{\star} H Y P O-O R S$ greater than RP-ORS, RS-ORS, and WHO-ORS; $p<0.002$.

tions $(\mathrm{p}<0 \cdot 02)$. Water absorption was similar from RS-ORS and RP-ORS but despite having the same total glucose content, HYPO-ORS produced more water absorption than the rice based solutions $(\mathrm{p}<0.005)$

In secreting intestine (Fig 2) all the solutions reversed net secretion to net absorption but all three hypotonic ORS promoted more water absorption than WHO-ORS and UK-ORS $(\mathrm{p}<0.005)$. RS-ORS and RP-ORS promoted more water absorption in secreting intestine than did the hypotonic glucose monomer solution, HYPO-ORS ( $\mathrm{p}<0.007)$. Water absorption from rice based solutions in the secretory state was about $70 \%$ of that in the normal state compared with about $50 \%$ for all other ORS.

GLUCOSE ABSORPTION

In normal intestine glucose absorption (Fig 3) was greatest from UK-ORS and HYPO-ORS

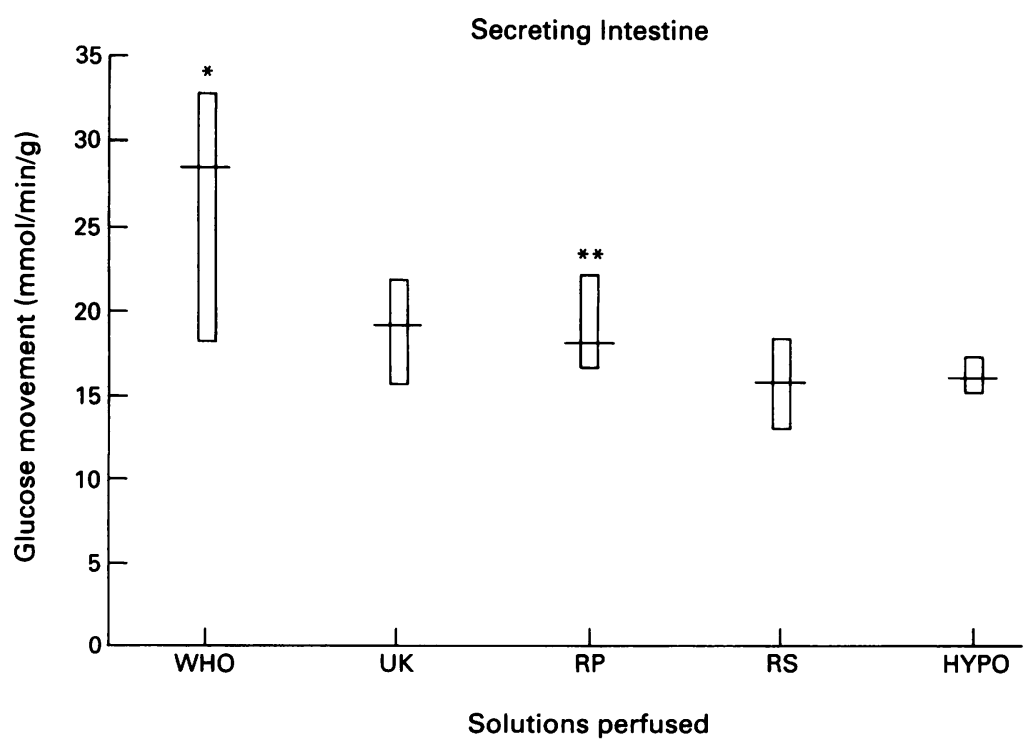

Figure 4: Net glucose movement in secreting rat small intestine. Data are presented as median and interquartile range. ${ }^{\star} W H O-O R S$ greater than $R S-O R S$ and $H Y P O-O R S ; p<0.004$; and interquartile range. ${ }_{\star \star} W H O-O R S$ greater than
${ }^{2} \mathrm{R}-O R S$ greater than $H Y P O-O R S ; p=0.03$. there being no significant difference between these solutions. Glucose absorption from RSORS was less than from HYPO-ORS and RPORS ( $p<0.002)$ and of these, HYPO-ORS led to more glucose absorption than RP-ORS $(\mathrm{p}=$ 0.002 ).

In the secretory state glucose absorption (Fig 4) from UK-ORS was not different from all the other ORS despite the very low water absorption. Similar glucose absorption was obtained from WHO-ORS, UK-ORS, and RP-ORS. Glucose absorption from HYPO-ORS and RSORS was almost identical and was less from either than from WHO-ORS $(\mathrm{p}<0.004)$. Glucose absorption from HYPO-ORS was less than from RP-ORS and WHO-ORS ( $p=0 \cdot 03)$.

SODIUM ABSORPTION

In normal intestine sodium absorption occurred from all the solutions (Fig 5) except for the low sodium UK-ORS $(\mathrm{p}<0.002)$. Sodium absorption from the rice-based solutions was similar but significantly less than sodium absorption from HYPO-ORS and WHO-ORS $(\mathrm{p}<0 \cdot 01)$. None of the ORS perfused were able to reverse the net secretory state for sodium induced by cholera toxin (Fig 6); sodium secretion was greater with UK-ORS ( $<<0.002)$.

CHLORIDE ABSORPTION

Table II summarises the data for net chloride movement. In normal intestine all ORS were associated with net chloride absorption but the highest chloride absorption was from HYPOORS $(\mathrm{p}<0.001)$. UK-ORS, which had the lowest chloride concentration, was associated with least chloride absorption $(\mathrm{p}<0.02)$. In secreting intestine UK-ORS led to chloride secretion $(\mathrm{p}<0.001)$ whereas the other ORS still led to net chloride absorption albeit much lower than in normal intestine.

RELATIONS BETWEEN WATER AND SOLUTE UPTAKE Tables III and IV summarise the data for individual and total solute movement in relation to net water movement. As expected there was direct correlation between total net solute absorption and net water absorption both in normal $(\mathrm{r}=0.76, \mathrm{p}<0.001)$ and secreting intestine $(\mathrm{r}=0.77, \mathrm{p}<0.001)$.

\section{Discussion}

All of the hypotonic ORS, whether they contained monomeric or polymeric carbohydrate as substrate, promoted more water absorption than the widely used hypertonic ORS and this accords well with the findings of other workers, both in human jejunum ${ }^{19}$ and in animal models. ${ }^{22} 27$ Both of the hypertonic ORS contained higher glucose concentrations and higher water absorption might have been expected from these solutions because of a greater stimulatory effect on active glucose transport. It is known, however, that a glucose concentration of $56 \mathrm{mmol} / \mathrm{1}^{26}$ can exert a maximal stimulatory effect on water absorption and concentrations as low as $30 \mathrm{mmol} / \mathrm{l}$, at least 


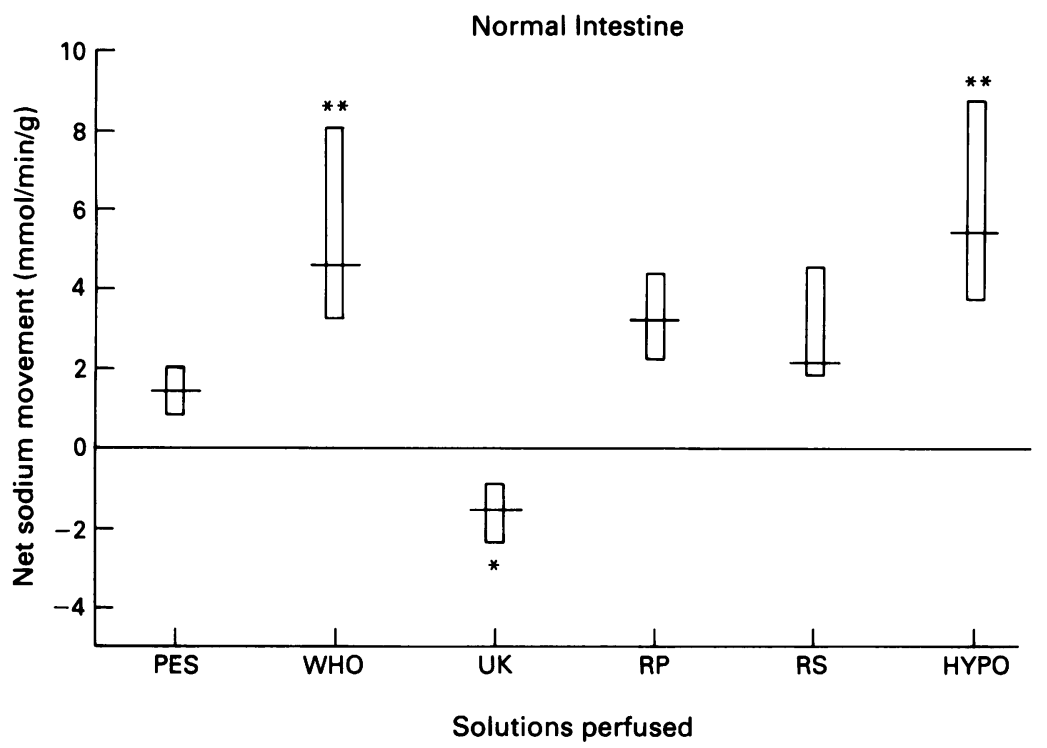

Figure 5: Net sodium movement in normal rat small intestine. Data are presented as median and interquartile range. ${ }^{\star} U K-O R S$ less than all the other $O R S ; p<0.002 ; \star \star W H O-O R S$ and $H Y P O-O R S$ greater than RP-ORS and RS-ORS; $p<0 \cdot 01$.

in short segments of human jejunum, can promote sodium absorption. ${ }^{28}$ Furthermore, restricting intraluminal sodium concentration in jejunal perfusion does not seem to limit glucose absorption. ${ }^{29}$ It is extremely unlikely therefore that the profound differences in water absorption between the hypertonic and hypotonic ORS are related to differences in sodium or glucose concentration. The ORS containing complex carbohydrate led to increased water absorption in secreting intestine compared with the hypotonic monomer solution HYPO-ORS. It would seem therefore that low osmolality is the dominant factor rather than glucose transport when it comes to promoting net water absorption and this contention is supported by the higher water absorption from the WHO-ORS compared with UK-ORS in secreting intestine, despite their similar glucose absorption. In human jejunum there is an inverse relation between water absorption and perfusate osmolality ${ }^{30}$ but below $250 \mathrm{mOsm} / \mathrm{kg}$ this inverse relation seems to disintegrate. ${ }^{31}$

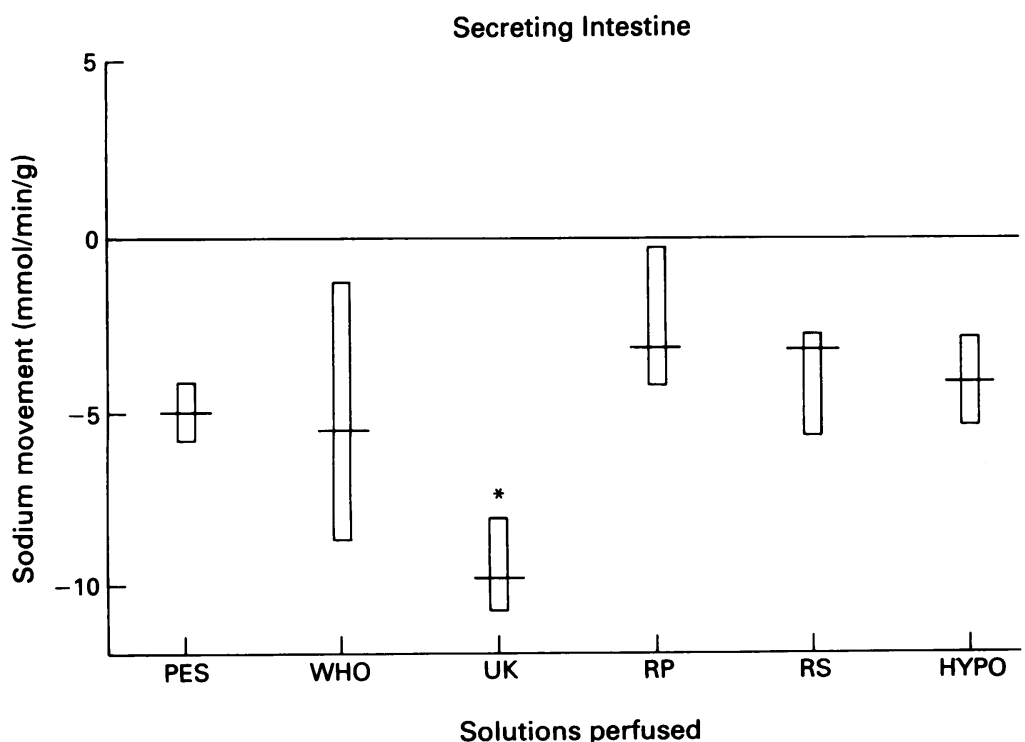

Figure 6: Net sodium movement in secreting rat small intestine. Data are presented as median and interquartile range. ${ }^{\star} U K-O R S$ less than all other $O R S ; p<0.002$.
Although solute dependent sodium absorption via the cotransport mechanism is of major therapeutic importance during diarrhoeal states, sodium is mainly absorbed from the jejunum through other passive processes such as electroneutral sodium chloride absorption and solvent drag. ${ }^{30}$ According to data from animal perfusion systems, net sodium movement even in glucose containing solutions is linearly related to sodium concentration of the perfusate and this pertains equally in secreting intestine, ${ }^{22}{ }^{24}$ although the threshold at which sodium absorption occurs is higher in the secretory state $(120 \mathrm{mmol} / \mathrm{l} v 60$ $\mathrm{mmol} / \mathrm{l})$. This linear relation has been confirmed with in vivo perfusion studies of human jejunum $^{32}$ where net absorption of sodium from isotonic enteral feeds containing glucose polymer occurred only when the sodium concentration was above $80-90 \mathrm{mmol} / \mathrm{l}$. It is not surprising therefore, that UK-ORS with its relatively low sodium concentration of $35 \mathrm{mmol} / 1$ did not promote net sodium absorption even in normal intestine, or that none of the solutions were able to reverse net sodium secretion to absorption in secreting intestine. In normal intestine the pattern of sodium absorption paralleled that for water absorption emphasising the importance of passive sodium absorption and solvent drag. These mechanisms were not able to offset the net sodium secretion induced by CT, however, which occurred despite net water absorption. In the whole gut of course, the reduction of this net sodium secretion by colonic salvage should be considered.

Glucose absorption from the hypotonic, monomeric, or polymeric ORS, paralleled water absorption whether the intestine was in a normal or secretory state. Exactly how glucose is absorbed from the jejunum remains undecided. Although saturation kinetics for glucose absorption from human jejunum have been shown ${ }^{33} 34$ suggesting that there is only active glucose transport, there is other evidence suggesting the participation of passive glucose absorption as well. ${ }^{35}$ Indeed recent work in a perfusion system with rat jejunum has added to the probability of there being substantial passive glucose absorption after changes in the intercellular junctions once active electrogenic sodium absorption is stimulated. ${ }^{36}$ Glucose absorption was highest in normal intestine from UK-ORS but not in secreting intestine and this certainly suggests an important role for passive glucose absorption due to solvent drag.

Rice starch is not a pure carbohydrate and on ignition about $0.4 \%$ remains as residue. Some of this will consist of protein. Aminoacid stimulated sodium absorption occurs independently of hexose stimulated sodium absorption via a separate nutrient-sodium cotransporter. There would therefore be an additive effect on the passive water absorption that occurs secondary to solute absorption. In our deliberations we have discounted that as a significant factor because of the negligible fraction of rice starch and rice powder that is not carbohydrate. Of course in the rice solutions used in the published field trials the protein content may have been as high as $10 \%$ and may therefore have contributed more to secondary salt and water absorption. 
TABLE II Net chloride movement in normal and secreting intestine

\begin{tabular}{|c|c|c|}
\hline $\begin{array}{l}\text { Solution } \\
\text { perfused }\end{array}$ & $\begin{array}{l}\text { Normal intestine. Mean } \\
\text { (SEM) chloride } \\
\text { movement (mmol/g/min) }\end{array}$ & $\begin{array}{l}\text { Secreting intestine. Mean } \\
\text { (SEM) chloride } \\
\text { movement (mmol/g/min) }\end{array}$ \\
\hline $\begin{array}{l}\text { PES } \\
\text { WHO-ORS } \\
\text { UK-ORS } \\
\text { HYPO-ORS } \\
\text { RS-ORS } \\
\text { RP-ORS }\end{array}$ & $\begin{array}{r}0.24(0.18) \\
7 \cdot 39(0.83) \\
1 \cdot 16(0.65) \\
11 \cdot 17(0.94) \\
6 \cdot 26(0.47) \\
7.51(0.42)\end{array}$ & $\begin{array}{c}-2.42(0.51) \\
3.34(1.61) \\
-3.62(0.33) \\
1.0(0.67) \\
1.87(0.58) \\
3.09(0.84)\end{array}$ \\
\hline
\end{tabular}

Abbreviations as in Table I.

The exact relation between net water uptake and osmolality is not entirely clear from our findings. Similarly no strong relations can be drawn from these data between osmolality and the glucose and electrolyte uptakes. There are some variables that confound adequate dissection of the potential interrelations. Firstly, the sodium and other electrolyte concentrations were not uniform among the ORS. Further studies with a defined glucose polymer where electrolyte composition is constant but osmolality and substrate concentration is varied with a range of monomer and polymer concentrations may lead to a better understanding of these phenomena.

Although it is not absolutely certain whether these findings from our animal model will be relevant in human beings, the close parallelism in the handling of ORS in both rat and human perfusion models ${ }^{37}$ is very encouraging. We believe that these findings suggest that osmolality is the key determinant of water absorption in both normal and secreting intestine and that it seems to be of particular importance in the secretory state. The success of complex carbohydrate containing ORS in clinical studies may be more closely related therefore to their very low osmolality relative to standard hypertonic monomer ORS than to the kinetic advantage factor or the increased substrate availability for glucose/sodium cotransport. Many field studies have used much higher loads of carbohydrate than we have because their main rationale was the ability to greatly increase available substrate without incurring a substantial osmotic penalty. Their goal was not necessarily to keep the resulting ORS hypotonic. Our solutions containing rice derived glucose polymer promoted the highest water obsorption in the secretory state but it is not known whether increasing the polymer concentration (but maintaining ORS hypotonicity) would enhance water absorption by further stimulating active glucose transport or whether water absorption would be jeopardised, even by a moderate increase in osmolality. The optimum polymer concentration therefore that would yield the best compromise between total glucose availability and low osmolality remains to be determined.

The standard hypertonic UK-ORS has already been replaced ${ }^{38}$ by the hypotonic monomer solution HYPO-ORS in the British National Formulary but the World Health Organisation understandably remains cautious about modifying what has been a highly successful and very widely tested remedy. Substantial changes recommending the widespread use of hypotonic ORS containing monomeric or polymeric glucose (defined glucose polymer or crude complex carbohydrate) would require more evidence of clinical benefit after rigorous controlled clinical trials.

This study was supported by a grant from Rorer Health Care Ltd. M J G Farthing gratefully acknowledges financial support by the Wellcome Trust.

1 Guerrant RL, Loahn JA, Williams EK. Acute infectious diarrhea: I epidemiology, etiology and pathogenesis. Pediatr Infect Dis F 1986; 5: 353-9.

2 Editorial. Water with sugar and salt. Lancet 1978; ii: 300.

3 Field $M$. New strategies for treating watery diarrhea. $N E$ ngl $\mathcal{F}$ Med 1977; 297: 1121-2.

4 Carpenter CCI, Greenough WB, Pierce NF. Oral rehydration therapy - The role of polymeric substates. $N$ Engl $\mathcal{F} M e d$ 1988; 319: 1346-8.

5 Molla AM, Sarker SA, Hossain M, Molla A, Greenough WB. Rice-powder electrolyte solution as oral therapy in diarrhoea due to Vibrio cholerae and Escherichia coli. Lancet 1982; i: 1317-9.

6 Patra FC, Mahalanabis D, Jalan KN, Sen A, Banerjee P. Is oral rice electrolyte solution superior to glucose electrolyte solution in infantile diarrhoea? Arch Dis Child 1982; 57 : 910-2.

TABLE III Total solute and water movement in normal intestine

\begin{tabular}{|c|c|c|c|c|c|c|c|}
\hline $\begin{array}{l}\text { Solutions } \\
\text { perfused }\end{array}$ & $\begin{array}{l}\text { Net water } \\
\text { movement } \\
(\mu g / g / \min )\end{array}$ & $\begin{array}{l}\text { Net glucose } \\
\text { movement } \\
(\text { mmol/g/min) }\end{array}$ & $\begin{array}{l}\text { Net sodium } \\
\text { movement } \\
(\text { mmol/g/min })\end{array}$ & $\begin{array}{l}\text { Net potassium } \\
\text { movement } \\
(\text { mmol/g/min })\end{array}$ & $\begin{array}{l}\text { Net chloride } \\
\text { movement } \\
\text { (mmol/g/min) }\end{array}$ & $\begin{array}{l}\text { Net total } \\
\text { electrolyte } \\
\text { movement } \\
(\text { mmol/lg/min })\end{array}$ & $\begin{array}{l}\text { Net total solute } \\
\text { movement } \\
(\mathrm{mmol} / \mathrm{g} / \mathrm{min})\end{array}$ \\
\hline $\begin{array}{l}\text { PES } \\
\text { WHO-ORS } \\
\text { UK-ORS } \\
\text { HYPO-ORS } \\
\text { RS-ORS } \\
\text { RP-ORS }\end{array}$ & $\begin{array}{c}2 \cdot 6 \\
88 \cdot 50 \\
63 \cdot 87 \\
250 \cdot 78 \\
182 \cdot 39 \\
195 \cdot 3\end{array}$ & $\begin{array}{l}-\overline{18} \cdot 97 \\
32 \cdot 96 \\
30 \cdot 13 \\
14 \cdot 01 \\
22 \cdot 49\end{array}$ & $\begin{array}{c}1.4 \\
5.53 \\
-1.97 \\
6.04 \\
2.94 \\
3.5\end{array}$ & $\begin{array}{r}-0.04 \\
3.63 \\
0.93 \\
5.26 \\
4.36 \\
5.03\end{array}$ & $\begin{array}{r}0 \cdot 24 \\
7 \cdot 39 \\
6 \cdot 66 \\
11 \cdot 17 \\
6 \cdot 26 \\
7 \cdot 62\end{array}$ & $\begin{array}{r}1 \cdot 64 \\
16 \cdot 55 \\
3 \cdot 76 \\
22 \cdot 59 \\
13 \cdot 68 \\
16 \cdot 24\end{array}$ & $\begin{array}{r}1 \cdot 64 \\
35 \cdot 52 \\
36 \cdot 72 \\
52 \cdot 72 \\
27 \cdot 69 \\
38 \cdot 73\end{array}$ \\
\hline
\end{tabular}

Abbreviations as in Table I.

TABLE IV Total solute and water movement in secreting intestine

\begin{tabular}{|c|c|c|c|c|c|c|c|}
\hline $\begin{array}{l}\text { Solutions } \\
\text { perfused }\end{array}$ & $\begin{array}{l}\text { Net water } \\
\text { movement } \\
(\mu g / g / \text { min })\end{array}$ & $\begin{array}{l}\text { Net glucose } \\
\text { movement } \\
(\text { mmol/g/min })\end{array}$ & $\begin{array}{l}\text { Net sodium } \\
\text { movement } \\
(\text { mmol/g/min })\end{array}$ & $\begin{array}{l}\text { Net potassium } \\
\text { movement } \\
(\text { mmol/g/min) }\end{array}$ & $\begin{array}{l}\text { Net chloride } \\
\text { movement } \\
\text { (mmol/g/min) }\end{array}$ & $\begin{array}{l}\text { Net total } \\
\text { electrolyte } \\
\text { movement } \\
(\text { mmol/lg/min })\end{array}$ & $\begin{array}{l}\text { Net total solute } \\
\text { movement } \\
(\mathrm{mmol} / \mathrm{g} / \mathrm{min})\end{array}$ \\
\hline $\begin{array}{l}\text { PES } \\
\text { WHO-ORS } \\
\text { UK-ORS } \\
\text { HYPO-ORS } \\
\text { RS-ORS } \\
\text { RP-ORS }\end{array}$ & $\begin{array}{c}-53 \cdot 19 \\
52 \cdot 78 \\
23 \cdot 87 \\
105 \cdot 1 \\
138 \cdot 32 \\
145 \cdot 46\end{array}$ & $\begin{array}{l}-\overline{25 \cdot 54} \\
18 \cdot 64 \\
16 \cdot 07 \\
15 \cdot 87 \\
19 \cdot 01\end{array}$ & $\begin{array}{l}-4 \cdot 96 \\
-5 \cdot 86 \\
-9 \cdot 48 \\
-4 \cdot 17 \\
-3 \cdot 26 \\
-2 \cdot 51\end{array}$ & $\begin{array}{r}-0 \cdot 94 \\
2 \cdot 21 \\
3 \cdot 36 \\
2 \cdot 69 \\
2 \cdot 8 \\
3 \cdot 8\end{array}$ & $\begin{array}{r}-2 \cdot 4 \\
3.34 \\
-3 \cdot 62 \\
1.01 \\
1.87 \\
3.09\end{array}$ & $\begin{array}{r}-8.32 \\
-0.31 \\
-9 \cdot 74 \\
-0.25 \\
1.61 \\
4.51\end{array}$ & $\begin{array}{c}-8 \cdot 32 \\
25 \cdot 23 \\
8 \cdot 9 \\
15 \cdot 82 \\
17 \cdot 48 \\
23 \cdot 52\end{array}$ \\
\hline
\end{tabular}


7 Molla AM, Ahmed SM, Greenough WB. Rice-based ora rehydration solution decreases the stool volume in acute diarrhoea. Bulletin of the World Health Organisation 1985 63(4): $751-6$.

8 Mehta MN, Subramaniam S. Comparison of rice water, rice electrolyte solution, and glucose electrolyte solution in the management of infantile diarrhoea. Lancet 1986; i: 843-5.

9 Allan AN, Sarker SA, Molla AM, Rahaman MM, Greenough WB. Hydrolysed wheat based oral rehydration solution for acute diarrhoea. Arch Dis Child 1987; 62: 440-4.

10 Bhan MK, Ghai OP, Khoshoo V, Vasudev AM, Bhatnagar S Arora MK, Stintzing G. Efficacy of Mung bean (lentil) and pop rice based rehydration solutions in comparison with the pop rice based rehydration solutions in comparison with the standard glucose electr

11 Murtaza A, Zulfiqar I, Khan S-R, Lindblad BS, Sahlgren BA, Apereia $A$. The benefits of the very early introduction of powder rice and dried edible seeds (dal moong) in the ora rehydration solution during the treatment of acute infectious diarrhoea. Acta Paediatr Scand 1987; 76: 861-4.

12 Molla AM, Molla A, Nath SK, Khatun M. Food-based oral rehydration salt solution for acute childhood diarrhoea. Lancet 1989; ii: 429-31.

13 Santosham M, Fayad IM, Hashem M, Goepp JG, Refat M, Sack RB. A comparison of rice-based oral rehydration solution and 'early feding' for the treatment of acute diarrhea solution and 'early feding' for the treatmen

14 Pizarro D, Posada G, Sandi L, Moran MBC, Moran JR. Ricebased oral electrolyte solutions for the management of infantile diarrhea. N Engl F Med 1991; 324: 517-21.

15 Jones BJM, Brown BE, Loran JS, Edgerton D, Kennedy JF, Stead JA, Silk DBA. Glucose absorption from starch hydrolysates in the human jejunum. Gut 1983; 24: 1152-60.

16 Jones BJM, Higgins BE, Silk DBA. Glucose absorption from maltotriose and glucose oligomers in the human jejunum. Clin Sci 1987; 72: 409-14.

17 Down F, Cohen MI, McNamara H, Finberg L. Intestinal osmolality and carbohydrate absorption in rats treated with polymerized glucose. Pediatr Res 1978; 12 : 24-6.

18 Saunders DR, Sillery JK. Absorption of carbohydrateelectrolyte solutions in rat duodeno-jejunum. Implications electrolyte solutions in rat duodeno-jejunum. Implications for the composition of or

19 Hunt JB, Elliott EJ, Farthing MJG. Efficacy of a standard United Kingdom oral rehydration solution (ORS) and a hypotonic ORS assessed by human intestinal perfusion. Alimentary Pharmacology and Therapeutics 1989; 3: 565-71.

20 Hunt JB, Elliott EJ, Fairclough PD, Clark ML, Farthing MJG. Water and solute absorption from hypotonic glucoseelectrolyte solutions in human jejunum. Gut 1992; 33: 47983

21 Report of an ESPGAN Working Group. Recommendations for composition of Oral Rehydration Solutions for the children of Europe. 7 Pediatr Gastroenterol Nutr 1992; 14: childre
22 Rolston DDK, Borodo MN, Kelly MJ, Dawson AM, Farthing MJG. Efficacy of oral rehydration solutions in a rat model of secretory diarrhoea. $\mathcal{F}$ Pediatr Gastroenterol Nutr 1987; 6 : 624-30.

23 Elliott EJ, Watson AJ, Walker-Smith JA, Farthing MJG. Effect of biocarbonate and efficacy of oral rehydration therapy: studies in an experimental model of secretory diarrhoea. Gut 1988; 29: 1052-7.

24 Elliott EJ, Watson AJ, Walker-Smith JA, Farthing MJG. Search for the ideal oral rehydration solution: studies in a model of secretory diarrhoea. Gut 1991; 32: 1314-20.

25 Roberts JD, Stewart R, Caseiro MC. Organic chemistry. New Yorts: WA Benjamin Inc, 1971: 495-502.

26 Sladen GE, Dawson AM. Interrelationships between the absorption of glucose, sodium and water by the normal absorption of glucose, sodium and water

27 Wapnir RA, Lifshitz F. Osmolality and solute concentrations - their relationship with oral rehydration solution effectiveness: An experimental assessment. Pediatr Res 1985; 19 894-8.

28 Fordtran JS. Stimulation of active and passive sodium absorption by sugars in the human jejunum. 7 Clin Invest 1974; 55 : 728-37.

29 Saltzman D, Rector FC, Fordtran JS. The role of intralumina sodium in glucose absorption in vivo. $\mathcal{F}$ Clin Invest 1972 151: $876-85$.

30 Fordtran JS, Rector FC, Carter NW. The mechanism of sodium absorption in the human small intestine. $\mathcal{F}$ Clin Invest 1968; 47: 884-900.

31 Soergel KH, Whalen GE, Harris JA. Passive movement of water and sodium across the human small intestinal mucosa. Appl Physiol 1968; 24: 40-8.

32 Spiller RC, Jones BHM, Silk DBA. Jejunal water and electrolyte absorption from two proprietary enteral feeds in man and importance of sodium content. Gut 1987; 28: man and

33 Holdsworth DC, Dawson AM. The absorption of monosaccharides in man. Clin Sci 1964; 27 : 371-9.

34 Read NW, Holdsworth CD, Levin RJ. Electrical measurement of intestinal absorption of glucose in man. Lancet 1974 ii: $624-7$.

35 Dawson DJ, Burrows PC, Lobley RW, Holmes R. The kinetics of monosaccharide absorption by human jejunum biopsies - evidence for active and passive processes. Digestion 1987; 38: 124 .

36 Pappenheimer JR, Reiss KZ. Contribution of solvent drag through intercellular junctions to absorption of nutrients by the small intestine of rat. $\mathcal{F} \mathrm{Membr} \mathrm{Biol} \mathrm{1987;100:} \mathrm{123-6.}$

37 Hunt JB, Elliott EJ, Farthing MJG. Comparison of rat and human intestinal perfusion models for assessing efficacy of oral rehydration solutions. Alimentary Pharmacology and Therapeutics 1991; 5: 49-59.

38 'Dioralyte'. British National Formulary 1991; September: 307. 